\title{
The Athymic Nude Rat
}

\section{Natural Cell-Mediated Cytotoxicity}

\author{
W. H. de Jong, ${ }^{1}$ P. A. Steerenberg, P. S. Ursem, A. D. M. E. Osterhaus, \\ J. G. Vos, AND E. J. RuITENBERG
}

National Institute of Public Health, P.O. Box I, Bilthoven. The Netherlands

Received October 23, 1979

\begin{abstract}
Homozygous rnu/rnu and heterozygous +/rnu rats were investigated and compared with each other for the existence of natural cell-mediated cytotoxicity. Investigated were total, adherent, and nonadherent cell populations from spleen, peritoneal cavity, and mesenteric lymph node. The natural killer (NK) cell activity was measured in a 4-hr ${ }^{51} \mathrm{Cr}$-release assay with a xenogencic murine YAC lymphoma target cell line. In both rnu/rnu and +/rnu rats the peritoneal cavity had the highest percentage of activity, while the spleen and mesenteric lymph node showed a lower activity. The mesenteric lymph node of $+/ r n u$ rats of $8-10$ weeks of age was found to express a very low activity, in contrast to a very high activity in $r n u / r n u$ rats. For almost every effector to target cell $(E: T)$ ratio investigated $(100,70,50$, and 10$)$, the natural killer cell activity in the nude rats was found to be significantly higher than in their thymus-bearing littermates. In comparison with that of $+/ r n u$ rats, NK activity in the nonadherent cell fractions of athymic rats was 50 to $60 \%$ higher in spleen cells, doubled in peritoneal cells, and increased 10-fold or higher in lymph node cells. Investigations of rat sera for the presence of antibodies against frequently occurring rodent viruses were negative.
\end{abstract}

\section{INTRODUCTION}

Natural killer (NK) cell activity is a unique cell-mediated mechanism that requires no presensitization. It has been found to exist in man and in various animal species including mice, rats, hamsters, and guinea pigs (1-3).

On the basis of their natural occurrence, cytocidal effects in vitro, and high concentrations in athymic nude mice and thymectomized mice and rats, Herberman and Holden (1) suggest NK cells to represent an important alternative for immunosurveillance against malignancies. Normal spleen cells of rats and positively selected NK cells of mice were found to prevent tumor growth in vivo $(4,5)$. Also a high positive correlation between NK cell activity in vitro and tumor resistance in vivo in mice was reported (6).

NK cell activity in rats and mice can be augmented by various agents including BCG and $C$. parvum; also, the inoculation of tumor cells can cause an increase in NK activity (1, 7-9). The negative influences of tumor cells on host NK cell activity, however, seem to be more important, as animals bearing established tumors express a lower cytotoxic activity than control animals $(3,10)$. Experimentally, NK cell activity can also be augmented by interferon or interferoninducing agents like poly I:C, lymphocytic choriomeningitis virus (LCMV) and Killham rat virus (8). In general, the boosting effect on NK cell activity lasts for only a few days.

\footnotetext{
${ }^{1}$ Fellow of the Koningin Wilhelmina Fonds of the National Cancer League.
} 
NK cell maturation and differentiation in mice appear to be thymus independent since both thymectomized and congenitally athymic (nude) mice express spontaneous NK cell activity $(11,12)$. However, the thymus has an important influence on NK cell activity, as athymic mice have increased activity. Also, neonatally and adult thymectomized rats have higher spontaneous cytotoxicity than thymusbearing controls (13).

The NK cell of the rat resembles the NK cell of the mouse as it is a small nonphagocytic nonadherent lymphocyte which has Fc receptors but lacks complement receptors and surface immunoglobulins (13-15). Similarly to that in the mouse, NK cell activity in rats depends on the age of the animals, with low activity at birth, reaching a platform at a certain age, followed by a decline $(4,14)$. Strain differences as great as in mice were not found in rats (4). Also, environmental influences seem to be of little importance, as no differences in activity were found between conventional and germ-free rats $(4,14)$.

Recently the athymic nude rat became available for immunologic and oncologic studies (16). Similar to that in the nude mouse, a depletion of the thymusdependent areas in the spleen and lymph nodes was observed. In contrast with the nude mouse, no alterations were found in the endocrine organs explaining the fertility of both sexes (17). The nude rat has absent $T$-cell function and a normal B-cell response. This was demonstrated by the failure to reject skin allografts, the absence of a delayed-type hypersensitivity reaction to tuberculin, the inability to generate an antibody response to the thymus-dependent antigens tetanus toxoid and ovalbumin, and the unresponsiveness of spleen cells upon stimulation with the mitogens phytohemagglutinin and concanavalin A. Against the thymusindependent antigen $E$. coli lipopolysaccharide, no reduction in the antibody response was found (18). Finally, the nude rat has enhanced macrophage activity as demonstrated by the increased phagocytosis and clearance of Listeria monocytogenes (19).

In this investigation the natural cell-mediated cytotoxicity of cells from the spleen, mesenteric lymph node, and peritoneal cavity of nude rats was investigated and compared with the activity of cells from their thymus-bearing littermates. As viral infections may enhance NK cell activity, sera of rats were tested for antibodies against frequently occurring rodent viruses.

\section{MATERIALS AND METHODS}

Animals. The origin of the athymic hooded rats used in this study was the breeding nucleus at the MRC Laboratory Animals Centre, Carshalton, U.K. Homozygous and heterozygous animals were produced in the institute by mating $r n u / r n u$ males with $+/ r n u$ females. The animals were bred and, after weaning, kept under conventional conditions with strictly hygienic isolation. For each experiment, comparisons were made with heterozygous littermates.

Effector cells. All effector cell populations from spleen, mesenteric lymph node, and peritoneal cavity were prepared using sterile techniques. Spleen and lymph node cells were harvested by pressing organ fragments through sterile nylon gauze $(100 \mu \mathrm{m})$ with the continuous addition of Hepes-buffered RPMI-1640 medium supplemented with penicillin $(100 \mathrm{IU} / \mathrm{ml})$, streptomycin $(100 \mu \mathrm{g} / \mathrm{ml})$, and $10 \%$ 
heat-inactivated fetal calf serum (all from GIBCO, Grand Island, N.Y.). This will be referred to as complete RPMI-1640. Peritoneal cells were harvested by massage of the peritoneal cavity after the injection of $5 \mathrm{ml}$ cold Hanks solution (without $\mathrm{Ca}^{2+}$ and $\mathrm{Mg}^{2+}$ ). The harvested suspension was reinjected two or three times. This total procedure was repeated once. After isolation, the cell suspensions were transferred to siliconized tubes and stored on melting ice. After centrifugation the pellets were resuspended in complete RPMI-1640. Pellets of spleen cells were treated with $\mathrm{H}_{2} \mathrm{O}(0.3 \mathrm{ml})$ for $10 \mathrm{sec}$ to lyse erythrocytes. This process was stopped by adding $5 \mathrm{ml}$ complete RPMI-1640 medium. Viable cells were counted in a Bürker-Türk chamber by the dye exclusion method using trypan blue.

The cytotoxicity was determined in the total, adherent, and nonadherent cell populations. To obtain the last two cell populations, the total population of each effector to target cell (E:T) ratio was divided into an adherent and a nonadherent fraction. For that purpose the cell populations were incubated for $2 \mathrm{hr}$ at $37^{\circ} \mathrm{C}$ in flat-bottomed removable polystyrene wells in tempex trays (Removawell System, Microtiter, Dynatech Companies, Zug, Switzerland). By vigorously pipetting, the nonadherent cells were collected and transferred to an empty well of the microtiter tray. The cytolytic assay was carried out with cell populations of individual animals; for each cell population and at each $E: T$ ratio, the assay was carried out in duplo. The effector cells were, depending on the number of cells available, investigated for cytotoxic activity at $\mathrm{E}: \mathrm{T}$ ratios of $100,70,50$, and 10 .

Tumor target cells. YAC cells of an in vitro grown murine cell line of A/Sn Moloney leukemia origin were used as target cells (12). For labeling, $100 \mu \mathrm{Ci}$ radioactive sodium chromate $\left({ }^{51} \mathrm{Cr}\right)$ in a $0.9 \%$ sodium chloride solution (Radiochemical Centre, Amersham, U.K.) was added to $1 \times 10^{6}$ Y AC cells in 0.1 $\mathrm{ml}$ complete RPMI-1640. The labeling time was $45 \mathrm{~min}$ at $37^{\circ} \mathrm{C}$ in a water bath with a rocking platform. After labeling, the cells were washed five times in Hanks solution (without $\mathrm{Ca}^{2+}$ and $\mathrm{Mg}^{2+}$ ) or complete RPMI-1640 and the number of viable cells was determined by the dye exclusion method.

Cytolytic assay. To reach an E:T ratio of, respectively, 100, 70, 50, and 10, a total of $1 \times 10^{6}, 7 \times 10^{5}, 5 \times 10^{5}$, and $1 \times 10^{5}$ viable effector cells in $100 \mu 1$ complete RPMI-1640 medium was added to the wells of microtiter trays. After dividing the total population into an adherent and a nonadherent fraction (see the preceding), $1 \times 10^{4}$ viable ${ }^{51} \mathrm{Cr}$-labeled target cells in $100 \mu \mathrm{l}$ medium were added to each well. After centrifugation at $1300 \mathrm{rpm}$ for $1 \mathrm{~min}$, the trays were incubated for $4 \mathrm{hr}$ at $37^{\circ} \mathrm{C}$ in a humidified atmosphere of $5 \% \mathrm{CO}_{2}$ in air. After a second centrifugation, half of the supernatant $(100 \mu \mathrm{l})$ was transferred to empty wells of microtiter trays. As the radioactivity was measured the next day, microtiter trays were stored overnight at $4^{\circ} \mathrm{C}$. Next, wells of the microtiter trays were removed and transferred to measuring tubes. The radioactivity was determined in a $\gamma$ counter and expressed as counts per minute (cpm).

The spontaneous release of ${ }^{51} \mathrm{Cr}$-labeled tumor target cells was calculated by incubating the tumor target cells in medium alone $\left(1 \times 10^{4}\right.$ cells in $\left.200 \mu \mathrm{l}\right)$. The release was calculated according to the following formula:

$$
\% \text { release }=\frac{2 \times \operatorname{cpm}(1 / 2 \text { supernatant })}{\operatorname{cpm}(\text { sediment }+1 / 2 \text { supernatant })+\operatorname{cpm}(1 / 2 \text { supernatant })} \times 100 .
$$


Spontaneous cytotoxic activity was expressed as percentage of specific release, i.e., percentage release minus percentage spontaneous release. The spontaneous release varied in the different assays from 5 to $7 \%$.

Virus serology. Before removing mesenteric lymph nodes, sera were collected individually from $10+/ r n u$ and 8 rnu/rnu rats for virus serology. Using conventional serologic methods (hemagglutination inhibition, HAI; complement fixation, CF; indirect immunofluorescence, IF), the sera were screened for the presence of antibodies against the following rodent viruses: mouse adenovirus $(\mathrm{CF}>5)$, vaccinia virus for the detection of ectromelia virus (IF $>10$ ), Sendai virus (HAI $>8$ ), parainfluenza virus type II, SV5 (HAI > 8), parainfluenza virus type III (HAI > 8), pneumonia virus of mice (HAI $>20)$, mouse hepatitis virus $(\mathrm{CF}>5$ ), Theiler virus GD VII (CF > 5), REO virus, SV12 (CF > 5), and lymphocytic choriomeningitis virus (IF $>10$ ).

Statistical analysis. The distribution-free Wilcoxon test was used to calculate one-sided significances of differences between values for $r n u / r n u$ and $+/ r n u$ rats.

\section{RESULTS}

The spontaneous killing activity of spleen cells was found to be relatively high in the total cell population (Table 1). The killing activity of each individual animal was dependent on the $E: T$ ratio, being high at a ratio of 100 and very low at a ratio of 10. The activity in the nonadherent fraction was almost as high as in the total cell population, while the activity in the adherent cells was low. For almost each E:T ratio in all three cell populations, a significantly higher activity was found in the $r n u / r n u$ rats than in their $+/ r n u$ littermates. NK activity in the nonadherent fraction of rnu/rnu rats was $50-60 \%$ higher than that of their heterozygous littermates.

Since an insufficient number of cells was obtained, peritoneal cells were investigated only at E:T ratios of 70 and 10 . NK activity of rnu/rnu rats was significantly higher in the total population and in the adherent and nonadherent fractions at both E:T ratios (Table 2). At an E:T ratio of 70, the nonadherent fractions showed almost the same activity as the total population. However, in comparison with the spleen cells, a marked activity was also present in the adherent cells of both + $/ r n u$ and rnu/rnu rats at an E:T ratio of 70. At an E:T ratio of 10 in the rnu/rnu rats, a relatively high activity was present, which was caused by a high activity found in one of the four animals. Spontaneous killing activity in the nonadherent cells of rnu/rnu rats at E:T ratios of 70 and 10 was doubled and quadrupled, respectively, compared with the activity in $+/ r n u$ rats.

Mesenteric lymph node cells of 10 -week-old +/rnu rats had a very low or no detectable killing activity (Table 3). Because of the use of only three $+/ r n u$ animals and the great differences with the rnu/rnu animals, the experiment was repeated with 8-week-old rats. The results of this second experiment, as shown in Table 4, were equal to the results of the first experiment. In particular, the high activity in the rnu/rnu rats is striking, with values that are one order of magnitude higher than those found in $+/ r n u$ rats. In the adherent fraction of $+/ r n u$ rats, no activity was measured, whereas rnu/rnu rats expressed a very low activity.

In none of the animals tested were antibodies detected against viruses fre- 


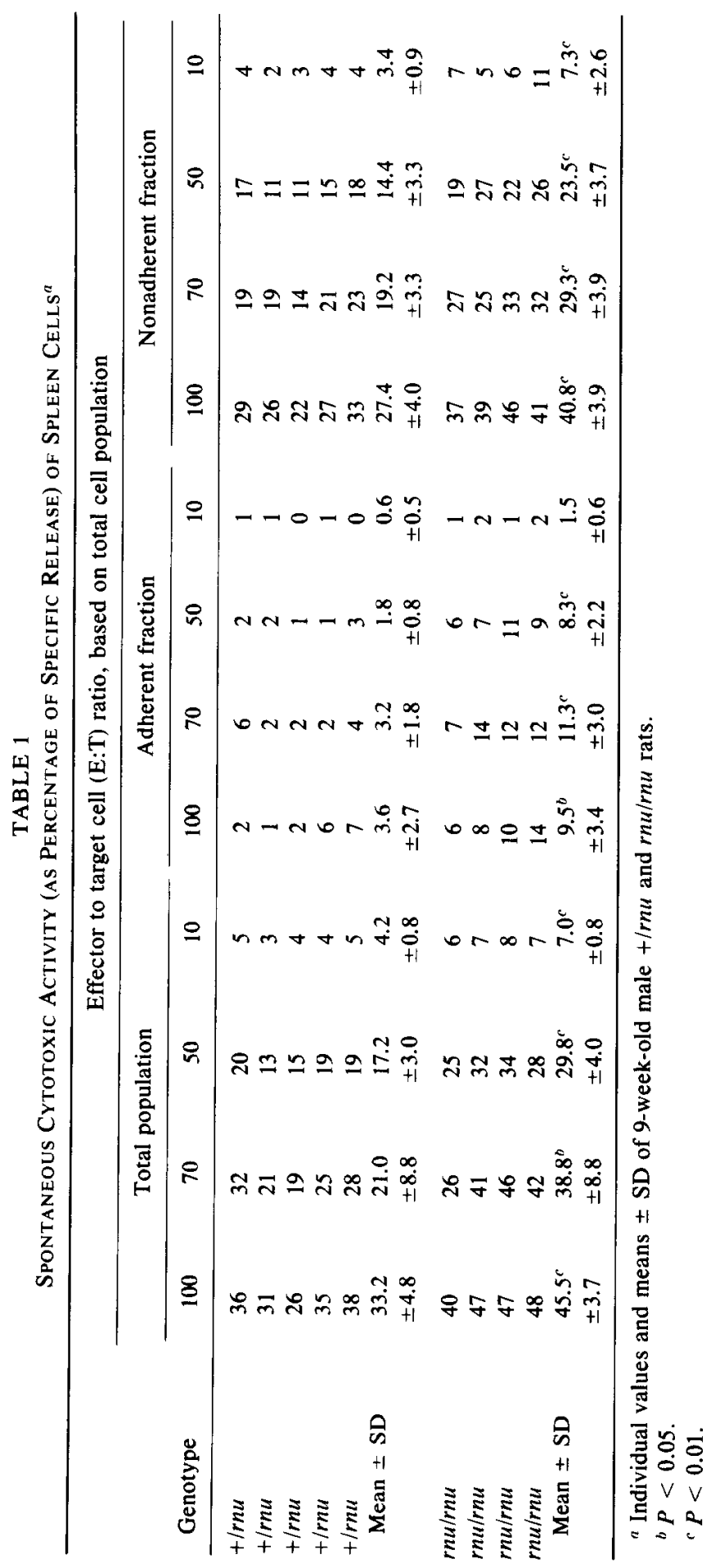


TABLE 2

Spontaneous Cytotoxic Activity (as Percentage of Specific Release) of Peritoneal Cells ${ }^{a}$

\begin{tabular}{|c|c|c|c|c|c|c|}
\hline \multirow[b]{3}{*}{ Genotype } & \multicolumn{6}{|c|}{ Effector to target cell $(\mathrm{E}: \mathrm{T})$ ratio, based on total cell population } \\
\hline & \multicolumn{2}{|c|}{ Total population } & \multicolumn{2}{|c|}{ Adherent fraction } & \multicolumn{2}{|c|}{ Nonadherent fraction } \\
\hline & 70 & 10 & 70 & 10 & 70 & 10 \\
\hline$+/ r n u$ & 44 & 12 & 21 & $\mathbf{0}$ & 35 & 8 \\
\hline$+/ r n u$ & 22 & 3 & 7 & $\mathbf{0}$ & 16 & 1 \\
\hline$+/ r n u$ & 22 & 2 & 3 & 0 & 16 & 2 \\
\hline$+/ r n u$ & 26 & 5 & 10 & 0 & 15 & 2 \\
\hline$+/ r n u$ & 44 & 9 & 9 & 0 & 40 & 8 \\
\hline \multirow[t]{2}{*}{ Mean $\pm S D$} & 31.6 & 6.2 & 10.0 & 0 & 24.4 & 4.2 \\
\hline & \pm 11.4 & \pm 4.2 & \pm 6.7 & \pm 0 & \pm 12.1 & \pm 3.5 \\
\hline rnu/rnu & 59 & 20 & 19 & 1 & 55 & 17 \\
\hline$r n u / r n u$ & 36 & 10 & 18 & 1 & 27 & 6 \\
\hline$r n u / r n u$ & 51 & 30 & 47 & 12 & 52 & 21 \\
\hline rnu/rnu & 57 & 26 & 46 & 4 & 58 & 17 \\
\hline \multirow[t]{2}{*}{ Mean $\pm S D$} & $50.8^{b}$ & $21.5^{r}$ & $32.5^{b}$ & $4.5^{d}$ & $48.0^{h}$ & $15.3^{b}$ \\
\hline & \pm 10.4 & \pm 8.7 & \pm 16.2 & \pm 5.2 & \pm 14.2 & \pm 6.4 \\
\hline
\end{tabular}

${ }^{a}$ Individual values and means $\pm \mathrm{SD}$ of 9 -week-old male $+/ r n u$ and $r n u / r n u$ rats. Since an insufficient number of cells were obtained, E:T ratios of 100 and 50 were not investigated.

${ }^{b} P<0.05$.

c $P<0.02$.

${ }^{i} \boldsymbol{P}<0.01$.

quently occurring in rodents. The serologic results in the $+/ r n u$ animals are especially indicative of the absence of intercurrent viral infections.

\section{DISCUSSION}

Natural cell-mediated cytotoxicity was found to be present in both $+/ r n u$ and $r n u / r n u$ rats. We investigated the total cell population and the adherent and nonadherent fractions of this population. In general, the nonadherent fraction expressed a spontaneous killing activity which was somewhat lower than the activity in the total population. Because of the method used, this could be due to an incomplete separation of the adherent and nonadherent cells. Comparing the killing activity of the different organs from rnu/rnu rats, the highest activity was found to be present in the peritoneal cells; spleen and mesenteric lymph node both expressed lower but considerable activity. This is in contrast with the nude mouse, where the peritoneal cavity showed a very low activity and the mesenteric lymph node showed a higher activity than the spleen (11). Probably species differences are involved. In $+/ r n u$ rats the highest activity was found in the peritoneal cells and lower but still considerable activity in the spleen cells, whereas lymph node cells had a very low activity. Nude rats expressed, in spleen, peritoneal cavity, and mesenteric lymph node, a significantly higher cytotoxic activity than their thymus-bearing +/rnu littermates at almost every E:T ratio. So, in general, the situation is similar to that in nude mice, which also express a higher spontaneous cytotoxicity compared to normal mice or heterozygous $+/ \ln u$ mice $(11,12)$. 


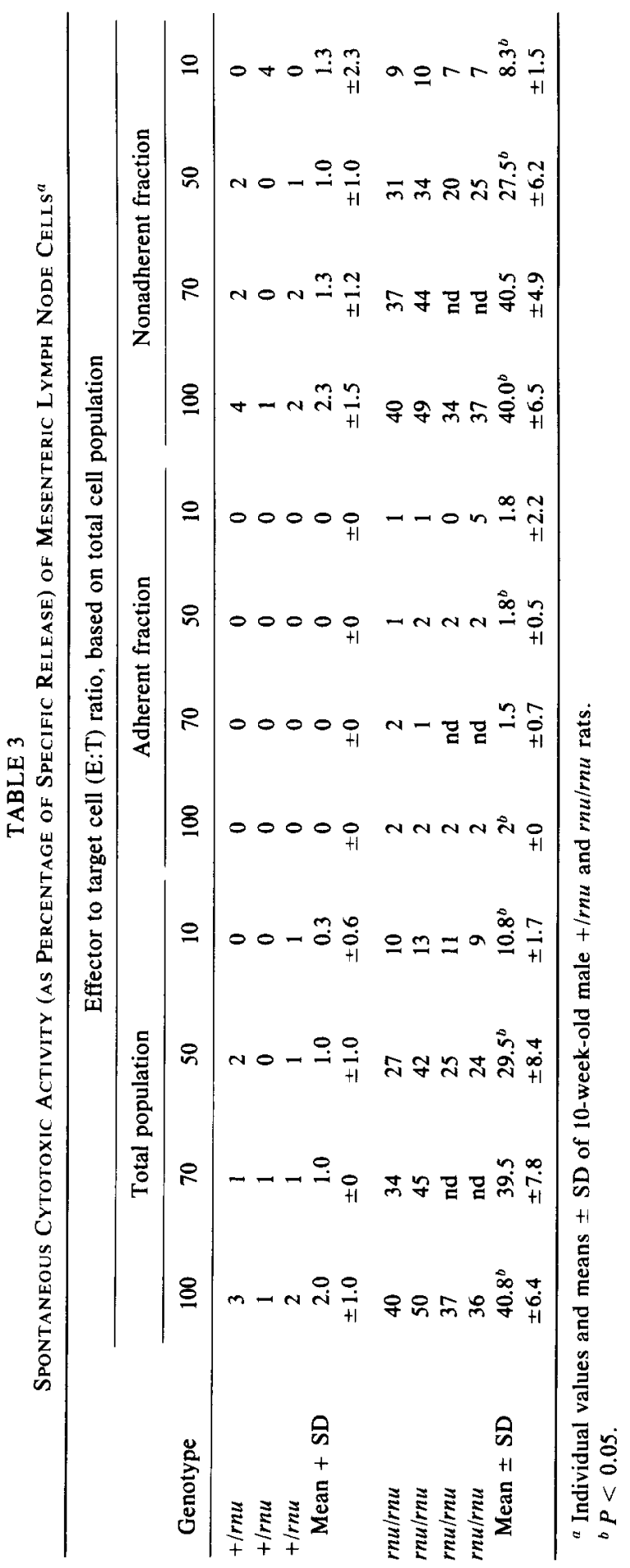




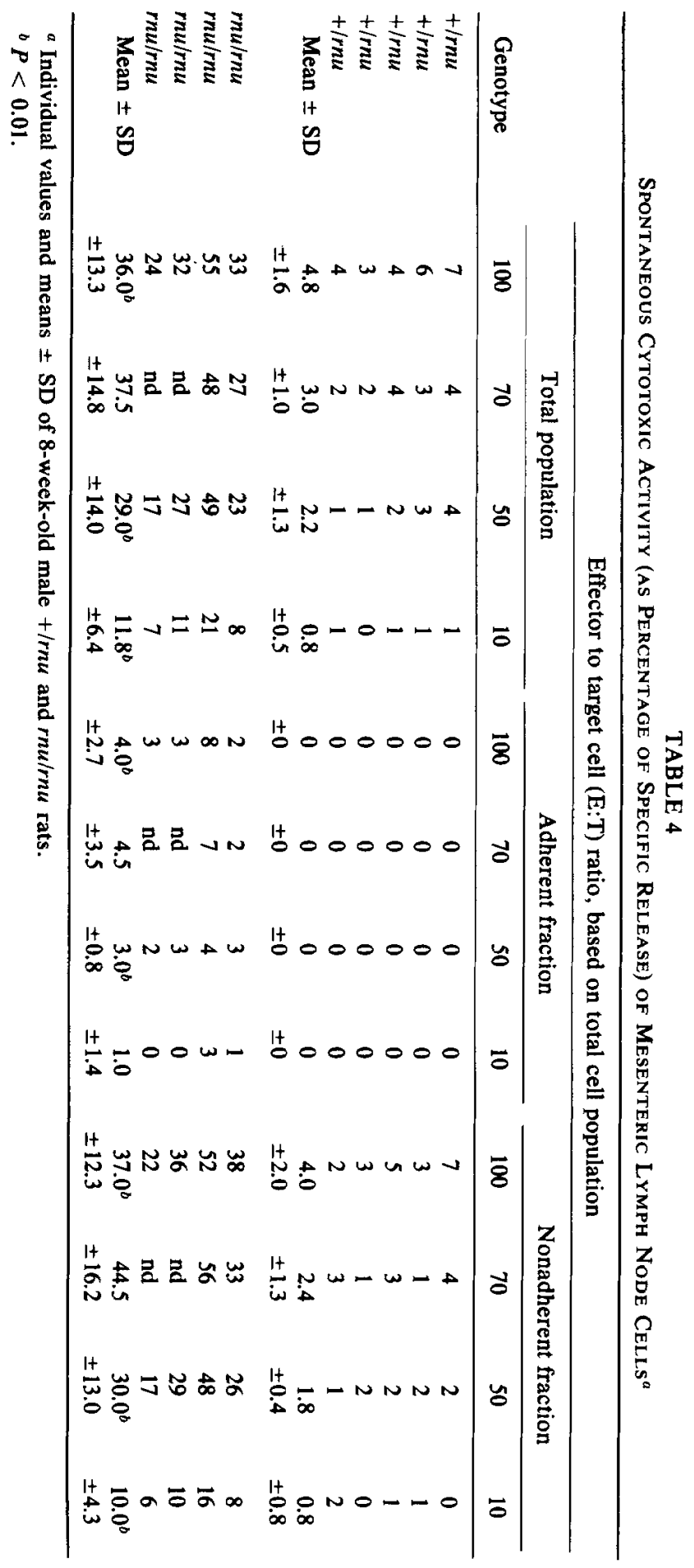


Also, in thymectomized rats the absence of the thymus was found to increase the NK cell activity (13).

The percentage specific release we found in nude rats was twofold the release found in thymectomized rats. This difference is probably caused by the use of different target cells, as the percentage increase in the spleen of nude rats was comparable to the increase in thymectomized rats, and even comparable to the increase reported for nude mice $(12,13)$, although greater differences between normal and nude mice have also been reported (11).

Our data concerning the spontaneous cytotoxic activity in the spleen of rats confirm the results of others (13-15). A high natural cytotoxicity has also been found to exist in the spleen of mice (11), guinea pigs (2), hamsters (3), and man (1).

In contrast to the low but detectable cytotoxic activity reported for peritoneal cells of mice and rats $(4,11,14,15)$, we found the highest activity in this cell population. Also, comparing our results with literature about rats, we found relatively high cytotoxic activities. The reason for these differences is not clear, but could be due to strain and target cell differences, although strain differences in rats were reported not to have a great influence on the NK cell activity (4).

After dividing the total cell population of the peritoneal cavity into an adherent and a nonadherent fraction, a striking cytotoxic activity was found to be present in the adherent fraction (Table 2). In mice, Tracey et al. (7) found a very low cytotoxic activity in the adherent population of peritoneal cells. In our assays, some contamination of nonadherent cells was always present. However, in assays with spleen and lymph node cells a very low activity was found (Tables 1, 3, and 4). The cause of this high activity in the adherent cells of the peritoneal cavity could be the presence of natural cytotoxic macrophages.

At the time of the cytolytic assay with mesenteric lymph node cells, the animals were 1 week older than in the assays with spleen and peritoneal cells. Low or almost no detectable activities were found in the $+/ r n u$ animals. As, for mice and rats, an age-related decline of NK cell activity has been reported $(4,11,14)$ and this decline in rats can be completed in 1 week (14), the experiment with mesenteric lymph node cells was repeated with animals of a younger age. In the second assay, performed with animals 8 weeks of age, similar results were obtained as with animals 10 wecks of age. So it is concluded that, for that particular age $(8-10$ weeks), the NK cell activity in the mesenteric lymph nodes of $+/ r n u$ rats is very low. This confirms the results of several authors who also found a low activity in lymph nodes of rats $(4,14,15)$. The difference between the activity in the mesenteric lymph node of +/rnu and rnu/rnu was extremely great. This could be due partly to the general difference which was found between the $+/ r n u$ and $r n u / r n u$ rats, but also age influences could play a role, as it is known that the age-related decline of NK cell activity in nude mice appears to be a gradual process with persistence of activity for longer periods of time (1). So it would be useful to investigate the influence of age on the NK cell activity in the $+/ r n u$ and rnu/rnu rat.

\section{REFERENCES}

1. Herberman, R. B., and Holden, H. T., Advan. Cancer Res. 27, 305, 1978.

2. Altman, A., and Rapp, H. J., J. Immunol. 121, $2244,1978$. 
3. Datta, S. K., Gallagher, M. T., and Trentin, J. J., Int. J. Cancer 23, 728, 1979.

4. Shellam, G. R., and Hogg, N., Int. J. Cancer 19, 212, 1977.

5. Kasai, M., Leclerc, J. C., McVay-Boudreau, L., Shen, F. W., and Cantor, H., J. Exp. Med. 149, $1260,1979$.

6. Haller, O., Hansson, M., Kiessling, R., and Wigzell, H., Nature (London) 270, 609, 1977.

7. Tracey, D. E., Wolfe, S. A., Durdik, J. M., and Henney, C. S., J. Immunol. 119, 1145, 1977.

8. Oehler, J. R., Lindsay, L. R., Nunn, M. E., Holden, H. T., and Herberman, R. B., Int. J. Cancer 21, 210, 1978.

9. Djeu, J. Y., Heibaugh, J. A., Holden, H. T., and Herberman, R. B., J. Immunol. 122, 182, 1979.

10. Becker, S., and Klein, E., Eur. J. Immunol. 6, 892, 1976.

11. Herberman, R. B., Nunn, M. E., and Lavrin, D. H., Int. J. Cancer 16, 216, 1975.

12. Kiessling, R., Klein, E., and Wigzell, H., Eur. J. Immunol. 5, 112, 1975.

13. Shellam, G. R., Int. J. Cancer 19, 225, 1977.

14. Nunn, M. E., Djeu, J. Y., Glaser, M., Lavrin, D. H., and Herberman, R. B., J. Nat. Cancer Inst. 56, 393, 1976.

15. Oehler, J. R., Lindsay, L. R., Nunn, M. E., and Herberman, R. B., Int. J. Cancer 21, 204, 1978.

16. Festing, M. F., May, D., Connors, T. A., Lovell, D., and Sparrow, S., Nature (London) 274, 365, 1978.

17. Vos, J. G., Berkvens, J. M., and Kruijt, B. C., Clin. Immunol. Immunopathol. 15, 213, 1980.

18. Vos, J. G., Kreeftenberg, J. G., Kruijt, B. C., Kruizinga, W., and Steerenberg, P. A., Clin. Immunol. Immunopathol. 15, 229, 1980.

19. Vos, J. G., de Jong, W. H., Kruizinga, W., van Noorle Jansen, L. M., and Steerenberg, P. A., In preparation. 